\title{
Compósitos de poli(álcool vinílico) Contendo Hidroxissais Lamelares de Zinco, Intercalados com Corantes Aniônicos Azo (Tropaeolina 0 e Tropaeolina 00)
}

\author{
Marlon Luiz Neves da Silva, Rafael Marangoni, Aline Hara da Silva, Fernando Wypych \\ Departamento de Química - Universidade Federal do Paraná, UFPR \\ Wido Herwig Schreiner \\ Departamento de Física - Departamento de Química - Universidade Federal do Paraná, UFPR
}

\begin{abstract}
Resumo: Hidroxissais lamelares de zinco foram intercalados com corantes aniônicos azo, obtendo-se pigmentos de coloração laranja. Os materiais foram caracterizados por difração de raios X (XRD), espectroscopia vibracional na região do infravermelho com transformada de Fourier (FTIR), análise térmica (TGA/DTA/DSC) e espectroscopia fotoeletrônica de raios X (XPS). Após caracterização, os pigmentos lamelares foram dispersos em uma matriz de poli(álcool vinílico) - PVA, em concentrações variáveis, em relação à massa de PVA. Filmes homogêneos, transparentes e coloridos foram obtidos pelo método de "casting" úmido e mantidos em dessecador em umidade controlada de $65 \%$ por uma semana e avaliados quanto às suas propriedades mecânicas. Devido às diferentes polaridades dos ânions intercalados, diferentes comportamentos foram observados para os pigmentos quando utilizados como cargas em PVA. Esse trabalho abre uma frente de pesquisas na utilização de hidroxissais lamelares intercalados com corantes aniônicos, como cargas alternativas em materiais compósitos poliméricos.
\end{abstract}

Palavras-chave: Hidroxissais lamelares, poli(álcool vinílico) - PVA, corantes azo laranja, compósitos coloridos, propriedades mecânicas.

\section{Poly(vinyl alcohol) Composites Containing Layered Hydroxide Salts, Intercalated with Anionic Azo Dyes (Tropaeolin 0 and Tropaeolin 0)}

\begin{abstract}
Layered zinc hydroxide salts were intercalated with anionic azo dyes, obtaining orange pigments. The materials were characterized by X-ray diffraction (XRD), Fourier Transform Infrared spectroscopy (FTIR), thermal analysis (TGA/DTA/DSC) and X-ray photoelectron spectroscopy (XPS). After characterization, the layered pigments were dispersed into a matrix of poly(vinyl alcohol) - PVA, in variable concentrations, in relation to the PVA mass. Homogeneous, transparent and colorful films were obtained by wet casting method and kept in a desiccator at $65 \%$ of humidity for one week and evaluated in relation to their mechanical properties. Owing to the different intercalated anions polarities, different behaviors were observed for both pigments when used as fillers in PVA. This work opens a research front in the utilization of layered hydroxide salt intercalated with anionic dyes, as alternative fillers in polymer composite materials.
\end{abstract}

Keywords: Layered hydroxide salts, poly(vinyl alcohol) - PVA, orange azo dyes, colored composites, mechanical properties.

\section{Introdução}

Após o desenvolvimento dos primeiros nanocompósitos poliméricos reforçados com argilominerais, reportados pelo grupo da Toyota do Japão nos início dos anos $90^{[1-3]}$, muitos são os trabalhos que buscam materiais alternativos para serem usados como cargas em polímeros. Devido às suas características suigeneris, a exemplo dos argilominerais, os materiais lamelares sintéticos são candidatos ideais para este fim. Dentre essas características podemos citar a utilização de metais não tóxicos e abundantes na natureza, processo de síntese em um único passo, obtenção de cristais com tamanho e morfologia controláveis, alta razão de aspecto (razão comprimento ou largura/altura), alta área superficial, possibilidade de serem delaminados ou esfoliados seja em solução quanto no polímero fundido, de serem modificados de forma a alterar as suas características químicas superficiais, do amplo controle da densidade de cargas das lamelas, entre outros.

Os hidróxidos duplos lamelares (HDLs) foram os primeiros a serem investigados como substituintes naturais dos argilominerais ${ }^{[4-8]}$. Os HDLs possuem uma estrutura baseada no mineral Brucita $\left(\mathrm{Mg}(\mathrm{OH})_{2}\right)$, onde parte dos cátions magnésio coordenados octaédricamente à íons hidroxila, são substituídos isomorficamente por cátions trivalentes, gerando um excesso de carga das lamelas, que é compensada pela intercalação de ânions hidratados. Os HDLs possuem uma formula genérica do tipo $\left[\mathrm{M}^{+2}{ }_{1-\mathrm{x}} \mathrm{M}^{+3}{ }_{\mathrm{x}}(\mathrm{OH})_{2}\right]^{\mathrm{x}-}\left(\mathrm{A}^{-\mathrm{n}}\right)_{\mathrm{x} / \mathrm{n}} \cdot \mathrm{yH}_{2} \mathrm{O}$, onde $\mathrm{M}^{+2}$ e $\mathrm{M}^{+3}$ representam respectivamente os cátion divalentes e trivalentes da lamela e $\mathrm{A}^{-\mathrm{n}}$. $\mathrm{yH}_{2} \mathrm{O}$ representa o ânion hidratado intercalado ${ }^{[9]}$. Uma série de metais pode fazer parte da lamela, embora uma correta combinação entre o cátion divalente e trivalente seja necessária Tipicamente os metais podem ser: $\mathrm{M}^{+2}=\mathrm{Mg}, \mathrm{Ca}, \mathrm{Sr}, \mathrm{Mn}, \mathrm{Fe}, \mathrm{Co}, \mathrm{Ni}, \mathrm{Cu}, \mathrm{Zn}$, $\mathrm{Cd}, \mathrm{M}^{3+}=\mathrm{Al}, \mathrm{Cr}, \mathrm{Fe}, \mathrm{Sc}, \mathrm{Ga}, \mathrm{Y}, \mathrm{In}, \mathrm{Ce}$, além de alguns excessões como $\mathrm{M}^{+}=\mathrm{Li}$ e $\mathrm{M}^{4+}=\mathrm{Zr}$, Pd, Sn. Uma ampla gama de ânions podem ser intercalados, tipicamente, $\mathrm{F}^{-}, \mathrm{Cl}^{-}, \mathrm{Br}^{-}, \mathrm{I}^{-}, \mathrm{BO}_{3}{ }^{3-}, \mathrm{CO}_{3}{ }^{2-}$, $\mathrm{NO}_{3}^{-}, \mathrm{Si}_{2} \mathrm{O}_{5}^{2-}, \mathrm{HPO}_{4}^{2-}, \mathrm{SO}_{4}^{2-}, \mathrm{ClO}_{4}^{-}, \mathrm{AsO}_{4}^{3-}, \mathrm{SeO}_{4}{ }^{2-}, \mathrm{BrO}_{4}^{-}, \mathrm{VO}_{4}^{3-}$, $\mathrm{CrO}_{4}^{2-}, \mathrm{MnO}_{4}^{-}, \mathrm{Fe}(\mathrm{CN})_{6}{ }^{2-}, \mathrm{CH}_{3} \mathrm{COO}^{-}, \mathrm{C}_{6} \mathrm{H}_{5} \mathrm{COO}^{-}, \mathrm{C}_{12} \mathrm{H}_{25} \mathrm{COO}^{-}$, $\mathrm{C}_{6} \mathrm{H}_{5} \mathrm{SO}_{3}^{-}$, ânions poliméricos, etc.

Mais recentemente, os hidroxissais lamelares (HSLs) também foram utilizados como cargas em nanocompósitos poliméricos ${ }^{[10-13]}$. Os HSLs são estruturalmente semelhantes aos HDLs, no entanto a capacidade de troca aniônica destes compostos é originada de forma distinta do que nos HDLs. A formulação típica pode ser descrita como $\mathrm{M}^{2+}(\mathrm{OH})_{2-\mathrm{x}}\left(\mathrm{A}^{\mathrm{n}-}\right)_{\mathrm{x} / \mathrm{n}} \cdot \mathrm{yH}_{2} \mathrm{O}$, onde $\mathrm{M}^{2+}$ é um cátion

Autor para correspondência: Fernando Wypych, Laboratório de Química de Materiais Avançados - LAQMA, Departamento de Química, Centro de Pesquisa em Química Aplicada - CEPESQ, Universidade Federal do Paraná - UFPR, CP 19081, CEP 81531-980, Jardim das Américas, Curitiba, PR, Brasil, e-mail:wypych@ufpr.br 
metálico divalente como por exemplo $\mathrm{Mg}^{2+}, \mathrm{Ni}^{2+}, \mathrm{Zn}^{2+}, \mathrm{Cu}^{2+}, \mathrm{Co}^{2+}$ e $\mathrm{A}^{\mathrm{m}-} \cdot \mathrm{yH}_{2} \mathrm{O}$, representa o ânion hidratado, intercalado ou ligado covalentemente à lamela. Exemplos típicos de ânions intercalados em HSLs são os íons $\mathrm{NO}_{3}^{-}, \mathrm{SO}_{4}{ }^{2-}, \mathrm{Cl}^{-}, \mathrm{CO}_{3}{ }^{2-}$, acetato, dodecilsulfato, entre outros.

Nos HSLs, dois metais podem ainda ser combinados na mesma estrutura, originando os hidroxissais duplos lamelares (HSDLs), com a seguinte formulação típica: $\left[\left(\mathrm{M}^{+2}{ }_{1-\mathrm{y}} \mathrm{Me}^{+2}{ }_{\mathrm{y}}\right)(\mathrm{OH})_{2-\mathrm{x}}\right]^{\mathrm{x}+}\left(\mathrm{A}^{\mathrm{n}-}\right)$ ${ }_{x / n} \cdot \mathrm{zH}_{2} \mathrm{O}$, onde $\mathrm{M}^{+2}$ e $\mathrm{Me}^{+2}$ representam dois metais divalentes. Combinações de $\mathrm{Zn} / \mathrm{Co}, \mathrm{Zn} / \mathrm{Ni}, \mathrm{Zn} / \mathrm{Cu}, \mathrm{Cu} / \mathrm{Ni}, \mathrm{Ni} / \mathrm{Cu}, \mathrm{Cu} / \mathrm{Zn}$ e $\mathrm{Cu} / \mathrm{Co}$ já foram descritas ${ }^{[14]}$ e muitas outras são passíveis de serem sintetizadas.

Com a intercalação de corantes entre as lamelas dos materiais lamelares, geram materiais coloridos que relembram o azul Maya $^{[15]}$, espera-se que esse tipo de material desperte interesse da comunidade científica. O azul Maya foi originalmente utilizado pela civilização Maya no México e surpreendentemente tem mantido a sua coloração bem preservada ao longo dos séculos em pinturas (cerca de 1200 anos), mesmo quando submetido às agressivas condições do meio ambiente. Recentemente descobriu-se que o azul Maya era obtido quando folhas de uma planta (Indigofera suffruticosa) eram moídas com paligorskita (um argilomineral poroso), gerando um material híbrido orgânico/inorgânico, onde as moléculas do índigo eram incorporadas nos canais de dimensões nanométricas da estrutura do argilomineral.

O PVA foi escolhido por ser "solúvel" em água, formar filmes transparentes com facilidade, não ter cheiro e nem sabor, ser atóxico, possuir moléculas polihidroxiladas o que irá permitir uma boa interação com a estrutura hidroxilada dos HSLs, além das suas variadas aplicações industriais. Nanocompósitos utilizando PVA como matriz polimérica são relativamente raros da literatura e salvo erros dos autores, poucos são os grupos brasileiros que utilizam materiais lamelares como cargas em polímeros, a maioria se concentrando em argilominerais modificados ${ }^{[16-20]}$. Além do fato de que poucos grupos brasileiros se dedicam à obtenção de materiais nanocompósitos poliméricos reforçados com materiais lamelares e de que os hidroxissais lamelares só passaram a ser utilizados como cargas no grupo de trabalho do autor do presente artigo, o objetivo do presente trabalho é apresentar pela primeira vez na literatura especializada brasileira, a intercalação de dois ânions de corantes azo de coloração laranja (tropaeolina 0 e tropaeolina 00) em uma HSL de zinco e utilização desses materiais como cargas em uma matriz do poli(álcool vinílico) - PVA, com o objetivo de gerar materiais poliméricos compósitos multifuncionais coloridos. Resultados semelhantes foram recentemente publicados pelo mesmo grupo de pesquisas do autor, utilizando-se outros corantes aniônicos azo ${ }^{[21,22]}$.

\section{Experimental}

\section{Obtenção dos compostos de intercalação}

Dissolveu-se 4,25 mmols de cada um dos sais de sódio dos corantes em $20 \mathrm{~mL}$ de água destilada. Em seguida essas soluções foram separadamente misturadas com $30 \mathrm{~mL}$ de uma solução aquosa contendo $15 \mathrm{mmols}$ de $\mathrm{ZnCl}_{2}$. O pH da mistura foi ajustado para valores próximos de 7, utilizando-se uma solução de $\mathrm{NaOH} 1 \mathrm{~mol} / \mathrm{L}$, $\mathrm{pH}$ em que o composto precipita. Considerando-se que o corante possui somente uma carga negativa, a razão molar corante:zinco esperada para a fórmula ideal do material $\left(\mathrm{Zn}_{5}(\mathrm{OH})_{8} \text { (corante }\right)_{2.0}$. $\mathrm{nH}_{2} \mathrm{O}$ ) de 0,4 foi diminuída para 0,28 , no intuito de formar pilastras dos ânions dos corantes e manutenção de íons hidroxila (ou íons cloreto) intercalados, o que possivelmente iria facilitar a penetração de moléculas de PVA entre as lamelas e aumentar a possibilidade de delaminação/esfoliação do material lamelar na matriz polimérica. A mistura foi deixada sob agitação a temperatura ambiente durante 24 horas e o produto sólido foi separado por centrifugação, lavado várias vezes com água destilada e secado em estufa a vácuo a temperatura de $60{ }^{\circ} \mathrm{C}$, por 24 horas. Observou-se que as soluções permaneceram coloridas após várias etapas de lavagem, demonstrando que o teor de corante nos HSLs esperado estaria bem abaixo do valor estequiométrico, conforme desejado.

Os corantes utilizados foram a tropaeolina 0 ou laranja VI $\left(\right.$ TR0 $\left.=\mathrm{C}_{12} \mathrm{H}_{9} \mathrm{~N}_{2} \mathrm{O}_{5} \mathrm{SNa}\right)$ e tropaeolina 00 ou laranja IV (TR00 $=\mathrm{C}_{18} \mathrm{H}_{14} \mathrm{~N}_{3} \mathrm{O}_{3} \mathrm{SNa}$ ), ambos na forma de sais de sódio e o poli(álcool vinílico) - PVA ( $\mathrm{MM}=72000 \mathrm{~g} \cdot \mathrm{mol}^{-1}$, grau de hidrólise de $98 \%$ ), possuindo grau analítico foram fornecidos pela Merck. O $\mathrm{ZnCl}_{2}$ e o $\mathrm{NaOH}$ foram fornecidos pela VETEC e utilizados sem purificação adicional.

\section{Obtenção dos filmes de PVA}

Os filmes foram preparados através do método de "casting" úmido, em água/etanol. Os HSLs intercalados com os corantes aniônicos, usados como carga foram suspensos em $4 \mathrm{~mL}$ de etanol e submetidos a um banho de ultra-som por uma hora, no intuito de desagregar e dispersar melhor o pigmento. Em seguida, a suspensão do pigmento foi vertida em um béquer contendo $500 \mathrm{mg}$ de PVA previamente "solubilizados" em $25 \mathrm{~mL}$ de água à $75^{\circ} \mathrm{C}$, sendo esta mistura mantida sob vigorosa agitação e temperatura, por um período de 30 minutos. A mistura homogênea foi transferida para uma placa de Petri de aço com diâmetro de aproximadamente $6 \mathrm{~cm}$ e o filme foi obtido pela evaporação dos solventes em uma estufa a vácuo, mantida a uma temperatura de $60{ }^{\circ} \mathrm{C}$ e pressão de $-400 \mathrm{mmHg}$, durante um período de 24 horas. Misturas nas proporções de $0,5,1,2$ e $4 \%$ foram obtidas, em relação à massa de polímero, a qual foi mantida constante para que os filmes tivessem aproximadamente as mesmas espessuras. Após secagem, os filmes transparentes e de coloração laranja homogênea foram facilmente removidos das placas de Petri, cortados em tiras de $1 \mathrm{~cm}$ de largura com o auxílio de um estilete e acondicionados em dessecador à umidade controlada de $65 \%$, para posteriores caracterizações.

\section{Métodos de caracterização}

As medidas de difração de raios X foram obtidas depositando-se os materiais em porta-amostras de alumínio e utilizando-se um difratômetro Shimadzu modelo XRD-6000. Utilizou-se uma fonte de radiação de cobre $\mathrm{CuK}_{\alpha}=1,5418 \AA$, corrente de $30 \mathrm{~mA}$ e tensão de $40 \mathrm{KV}$ e as medidas foram adquiridas a uma velocidade de varredura de $2 \%$ min e passo de 0,02 graus.

As medidas de espectroscopia vibracional na região do infravermelho (FTIR) foram obtidas pelo modo transmissão em um equipamento Bio-Rad, Modelo FTS 3500GX, mediante o uso de pastilhas de $\mathrm{KBr}$, com acumulação de 32 transientes na faixa dos 400 aos $4000 \mathrm{~cm}^{-1}$ e resolução de $4 \mathrm{~cm}^{-1}$.

As medidas simultâneas de TGA/DTA foram realizadas utilizando-se um equipamento Mettler Toledo TG/s-DTA 851 E. As amostras foram alocadas em cadinhos de platina e submetidas a um programa de aquecimento de $10{ }^{\circ} \mathrm{C} \cdot \mathrm{min}^{-1}$, sob fluxo de oxigênio de $50 \mathrm{~mL} / \mathrm{min}^{-1}$.

As medidas de calorimetria exploratória diferencial (DSC) foram realizadas em um equipamento Netzsch DSC 204 F1, empregando ciclos de aquecimento/resfriamento de $10{ }^{\circ} \mathrm{C} / \mathrm{min}$ e fluxo de nitrogênio de $40 \mathrm{~mL} / \mathrm{min}$. As amostras foram alocadas em cadinhos de alumínio e submetidas a um processo de aquecimento até a temperatura de $120{ }^{\circ} \mathrm{C}$ por 2 minutos e uma rampa de 

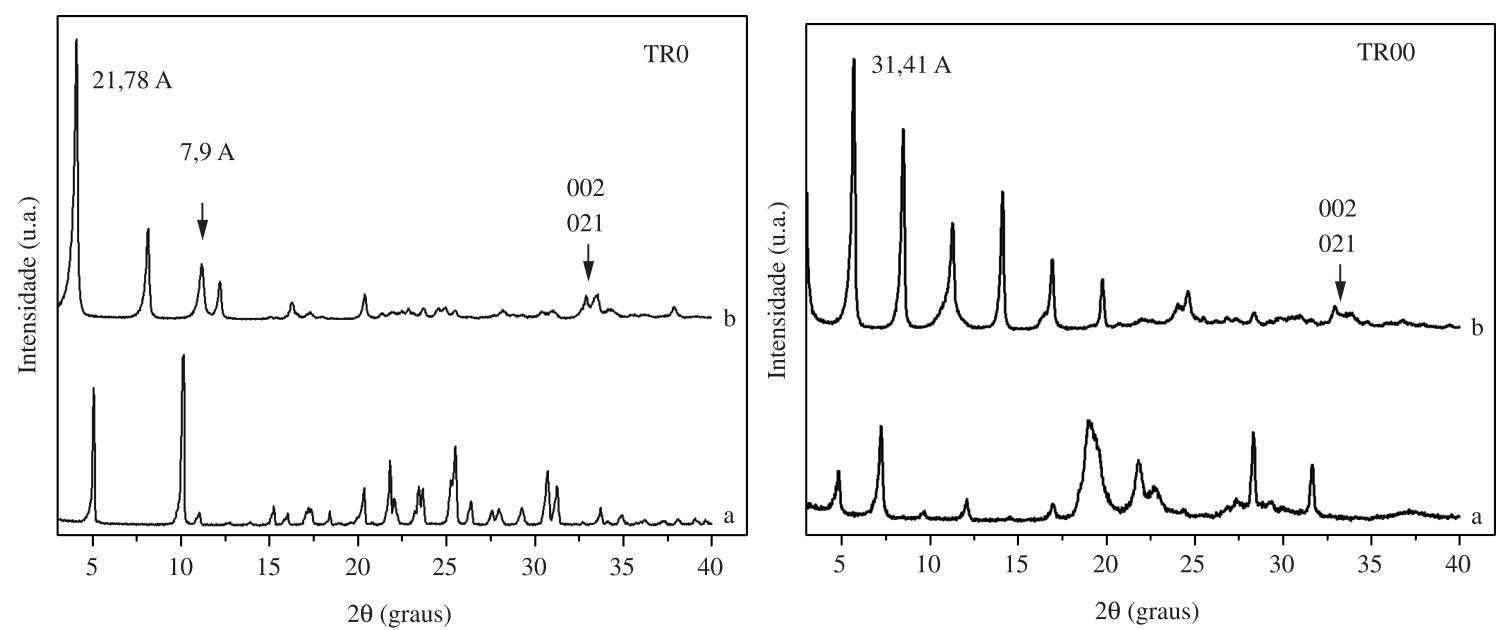

Figura 1. Difratogramas de raios $X$ dos sais de sódio dos corantes (a) e após intercalação no hidroxissal lamelar de zinco (b).

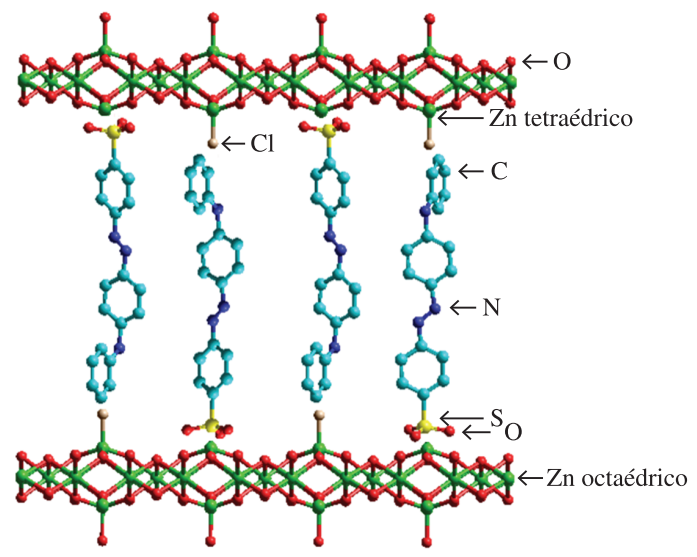

Figura 2. Representação esquemática da intercalação do ânion da tropaeolina 00, entre as lamelas do HSL de zinco. Os hidrogênios e as moléculas de água foram removidos para facilitar a visualização.

aquecimento/resfriamento de $20{ }^{\circ} \mathrm{C}$ até $235^{\circ} \mathrm{C}$, sendo o segundo ciclo utilizado para a detecção dos eventos térmicos das amostras.

As medidas de spectroscopia fotoeletrônica de raios (XPS) foram obtidas num equipamento VG Microtech ESCA3000, com uma pressão de base de $3 \times 10^{-10}$ mbar. Os espectros foram obtidos utilizando-se radiação $\mathrm{MgK}_{\alpha}$, com resolução de $0.8 \mathrm{eV}$ $\mathrm{e}$ as escalas de energia foram calibradas utilizando-se o pico do carbono adventício $(\mathrm{C} 1 \mathrm{~s})$ à $284.5 \mathrm{eV}^{[23]}$. A quantificação elementar foi realizada adquirindo-se os espectros com maior resolução e os elementos foram identificados de acordo com valores tabelados em um banco de dados comercial (3.2 Spectral Data Processing software $)^{[24]}$. Os espectros mostrados nas figuras correspondem às medidas brutas.

Para quantificar os teores de corantes intercalados nos HSLs, cerca de $10 \mathrm{mg}$ das amostras intercaladas com corantes foram secadas à $200{ }^{\circ} \mathrm{C}$ por 6 horas e dissolvidas em $\mathrm{HCl} 0.1 \mathrm{~mol} / \mathrm{L}$. As soluções resultantes foram diluídas, os $\mathrm{pHs}$ foram ajustados para valores próximos a 2 e as concentrações determinadas, utilizando-se um equipamento Shimadzu UV-2401PC e cubetas de quartzo de $10 \mathrm{~cm}$ de caminho óptico. $\mathrm{O}$ valor do $\mathrm{pH}$ da solução foi mantido ácido para evitar a precipitação de algum sal insolúvel, além de manter os picos de absorção dos corantes em posições constantes. Os valores obtidos foram comparados com curvas de calibração obtidas nas mesmas condições, utilizando-se sais de sódio dos corantes.
Os ensaios mecânicos de tração foram realizados em uma máquina universal Instron, modelo 5565 Universal Assay Apparatus, utilizando-se uma cela de carga de $1 \mathrm{KN}$. Para cada amostra, utilizou-se 5 corpos de prova, mantidos sob atmosfera controlada de $65 \%$ de umidade relativa do ar, por uma semana. Os corpos de prova tinham o formato de uma fita retangular de $1 \mathrm{~cm}$ de largura, $4 \mathrm{~cm}$ de altura e espessura média aproximada de $0,1 \mathrm{~mm}$. As distâncias entre garras do equipamento foram fixadas em $1 \mathrm{~cm}$ e os filmes foram presos através do uso de garras pneumáticas. Os ensaios foram realizados a uma velocidade de $5 \mathrm{~mm} / \mathrm{min}$ e com a sala de medida mantida a uma temperatura de $23 \pm 2{ }^{\circ} \mathrm{C}$. Os resultados foram analisados através de curvas Tensão versus Deformação, de onde foram extraídos o módulo de elasticidade (através do ajuste da curva na seção linear inicial até $1 \%$ de deformação pelo método dos mínimos quadrados), a tensão máxima e o alongamento.

\section{Resultados e Discussões}

Observa-se nos difratogramas de raios X (Figura 1), que uma série de picos de difração basais (100) característicos de compostos lamelares é observada. Em ambos os casos, a intercalação dos corantes ocorreu com sucesso, já que distâncias basais de 21,78 ̊̊ e $31,41 \AA$ foram obtidas para os compostos intercalados com os ânions derivados da TR0 e TR00, respectivamente. Essas distâncias, que foram obtidas dos picos de difração de maior ordem possível, correspondem às expansões basais de $11,78 \AA$ e $21,41 \AA$ ( $4,8 \AA$ da espessura da lamela da Brucita $+2,6 \AA \times 2$, atribuídos aos octaedros de zinco em ambos lados da lamela) ${ }^{[25]}$.

No difratograma de raios $\mathrm{X}$ do composto HSL-TR0, uma pequena contaminação de hidroxicloreto de zinco $\left(\mathrm{Zn}_{5}(\mathrm{OH})_{8} \mathrm{Cl}_{2} \cdot 2 \mathrm{H}_{2} \mathrm{O}\right)$ foi detectada (indicada com uma seta em 7,9 A $^{[26]}$, esta fase era esperada devido à restrição do teor de corante durante as sínteses. Observa-se também que nenhuma outra fase cristalina contaminante foi detectada, nem os sais de sódio dos corantes. As distâncias dos ânions dos corantes intercalados, ao longo do seu maior eixo são de 13,1 Å para a tropaeolina 0 e $19,4 \AA$ para a tropaeolina $00^{[27]}$, sugerindo que para ambos os casos a intercalação ocorre formando uma monocamada de forma interdigitalizada, onde a carga negativa do grupamento sulfonato está posicionada de forma alternada na direção superior e inferior da lamela, conforme demonstrado na Figura 2.

Quanto o composto HSL-TR0 é avaliado, o valor da expansão basal teórico $(21,78-4,8-(2,6 \times 2)=11,78 \AA)$ é ligeiramente menor que o comprimento do ânion intercalado $(13,1 \AA$ ), o que leva a crer que o ânion derivado da tropaeolina 0 está ligada à lamela de forma distinta do que a tropaeolina 00, maximizando o contato do ânion com a lamela do HSL e/ou aumentando o 
grau de inclinação devido a presença de água. Quanto os ânions da tropaeolina 0 e tropaeolina 00 são intercaladas em hidróxidos duplos lamelares ${ }^{[27,28]}$, os quais possuem lamelas com uma estrutura plana, as distância basais observada são de 21,4 Å e de 25,99 Å, respectivamente. Esses valores subtraídos das espessuras das lamelas da brucita $(4,8 \AA$ ) produzem valores de $16,6 \AA$ e $21,19 \AA$, respectivamente. Somente a tropaeolina 00 concorda muito bem com o valor obtido $(31,41-4,8-(2,6 \times 2)=21,41 \AA)$. Essa é uma forte evidência de que o ânion da tropaeolina 00 está ligado eletrostaticamente ao topo dos tetraedros de zinco e posicionado de forma perpendicular às lamelas (Figura 2). Para garantir que a estrutura da lamela é semelhante ao hidroxinitrato de zinco $\left(\mathrm{Zn}_{5}(\mathrm{OH})_{8}\left(\mathrm{NO}_{3}\right)_{2} \cdot 2 \mathrm{H}_{2} \mathrm{O}\right)$, picos não basais indexados com índices 002 e 021 foram identificados em ambas as amostras $\left(32,52^{\circ} \mathrm{e}\right.$ $33,01^{\circ}$ ) para o hidroxinitrato de zinco $^{[25]}, 32,90^{\circ}$ e $33,56^{\circ}$ para HSL-TR0 e $32,97^{\circ}$ e $33,79^{\circ}$ para HSL-TR00, respectivamente.

A Figura 3 mostra os espectros de FTIR dos sais de sódio dos corantes (a) e HSLs intercalados com os ânions dos corantes (b), onde resultados semelhantes foram observados para a adsorção de alaranjado $\mathrm{II}^{[29]}$ e intercalação de alaranjado de metila ${ }^{[30-32]}$, em hidróxidos duplos e hidroxissais lamelares. Para o sal de sódio da TR0 e após intercalação do respectivo ânion no hidroxissal lamelar (HSL-TR0), as bandas em $1593 \mathrm{~cm}^{-1}$ e $1420 \mathrm{~cm}^{-1}$ atribuídas à vibração da ligação $\mathrm{N}=\mathrm{N}$, são reduzidas a uma banda larga em 1573 e um ombro em $1602 \mathrm{~cm}^{-1}$. As bandas em 1627 são atribuídas à flexão da molécula de água estrutural. $\mathrm{Na}$ mesma região são observadas bandas relativas à ligação $\mathrm{C}=\mathrm{C}$ do anel aromático. A banda em $1120 \mathrm{~cm}^{-1}$, atribuída a vibração da ligação C-S, é deslocada para $1123 \mathrm{~cm}^{-1}$. As bandas simétricas e assimétricas do grupamento sulfonato em $1176 \mathrm{~cm}^{-1}\left(1224 \mathrm{~cm}^{-1}\right)$ e $1034 \mathrm{~cm}^{-1}$,

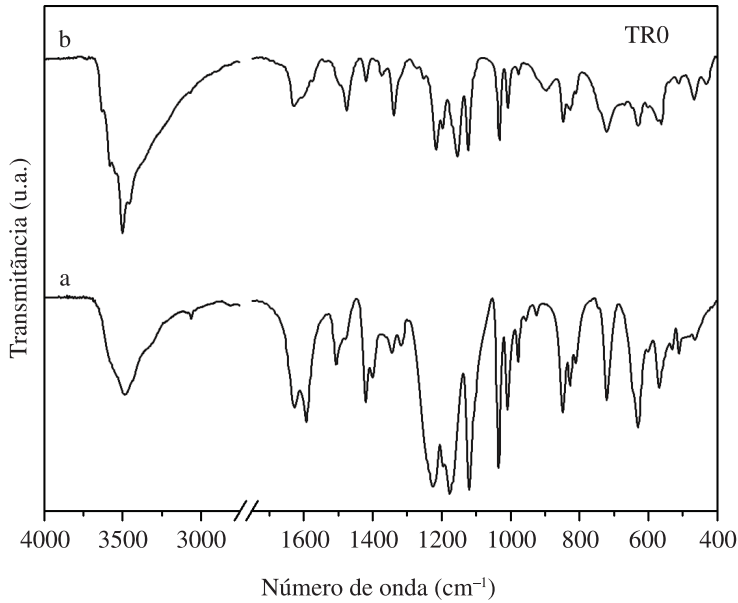

respectivamente, são desdobradas em várias bandas em 1215 , 1154,1123 e $1033 \mathrm{~cm}^{-1}$, o que atesta a interação do grupamento sulfonato às lamelas do HSL.

Para o sal de sódio da TR00 e após a intercalação do respectivo ânion no hidroxissal lamelar (HSL-TR00), as bandas em 1600 e $1398 \mathrm{~cm}^{-1}$, atribuídas a vibração da ligação $\mathrm{N}=\mathrm{N}$, são deslocadas para 1597 e $1435 \mathrm{~cm}^{-1}$. Na mesma região são observadas bandas relativas à ligação $\mathrm{C}=\mathrm{C}$ do anel aromático. As bandas simétricas e assimétricas do grupamento sulfonato em 1190 e $1051 \mathrm{~cm}^{-1}$, respectivamente, são deslocadas para $1201 \mathrm{~cm}^{-1}$ (ombro em $1170 \mathrm{~cm}^{-1}$ ) e $1033 \mathrm{~cm}^{-1}$. A banda em $1130 \mathrm{~cm}^{-1}$, atribuída à vibração da ligação C-S, é deslocada para $1124 \mathrm{~cm}^{-1}$. Observa-se a ausência da banda na região de 1627, o que nos leva a concluir que ao ânion da tropaeolina 00, não estão associadas moléculas de água. Em ambos os casos, bandas na região de $850-400 \mathrm{~cm}^{-1}$ são atribuídas às vibrações das ligações $\mathrm{Zn}-\mathrm{O}, \mathrm{Zn}-\mathrm{O}-\mathrm{Zn}, \mathrm{O}-\mathrm{Zn}-\mathrm{O}$, além do anel benzênico.

Devido à complexidade dos espectros de FTIR, qualquer conclusão mais precisa se torna especulativa, o que fica evidente porém são as alterações das bandas relativas ao grupamento sulfonato, o que mostra que a interação do ânion do corante com a lamela ocorre através desse grupo funcional, porém fica difícil inferir se a interação é puramente eletrostática ou covalente e a posição exata da ligação do grupamento sulfonato na lamela do HSL. A Figura 4 mostra medidas de espectroscopia fotoeletrônica de raios $\mathrm{X}$, dos HSL intercalados com os corantes aniônicos.

Nas amostras avaliadas, picos para os elementos S, C, N, O e Zn foram observados (Figura 4), porém como o XPS é uma técnica de superfície e os limites de detecção para o N o S são baixos, somente foi possível determinar o teor dos elementos da amostras de forma

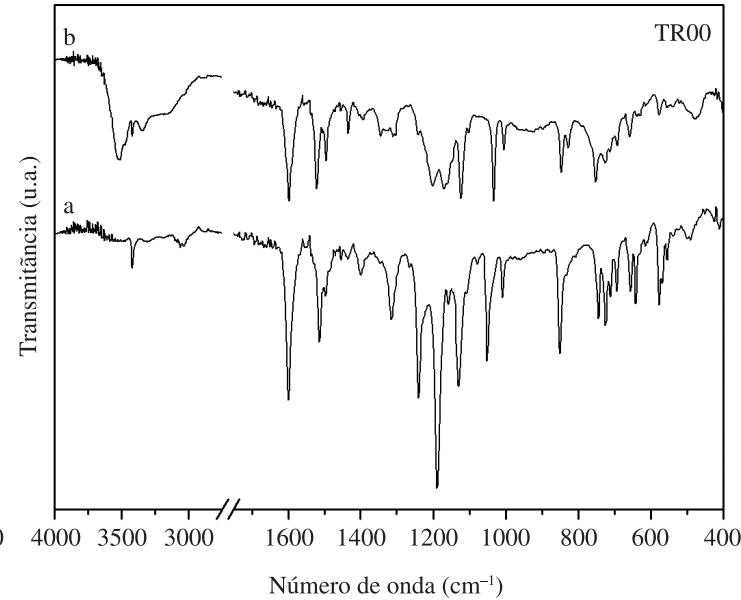

Figura 3. Espectros de FTIR dos sais de sódio dos corantes (a) e HSLs intercalados com os ânions dos corantes (b).
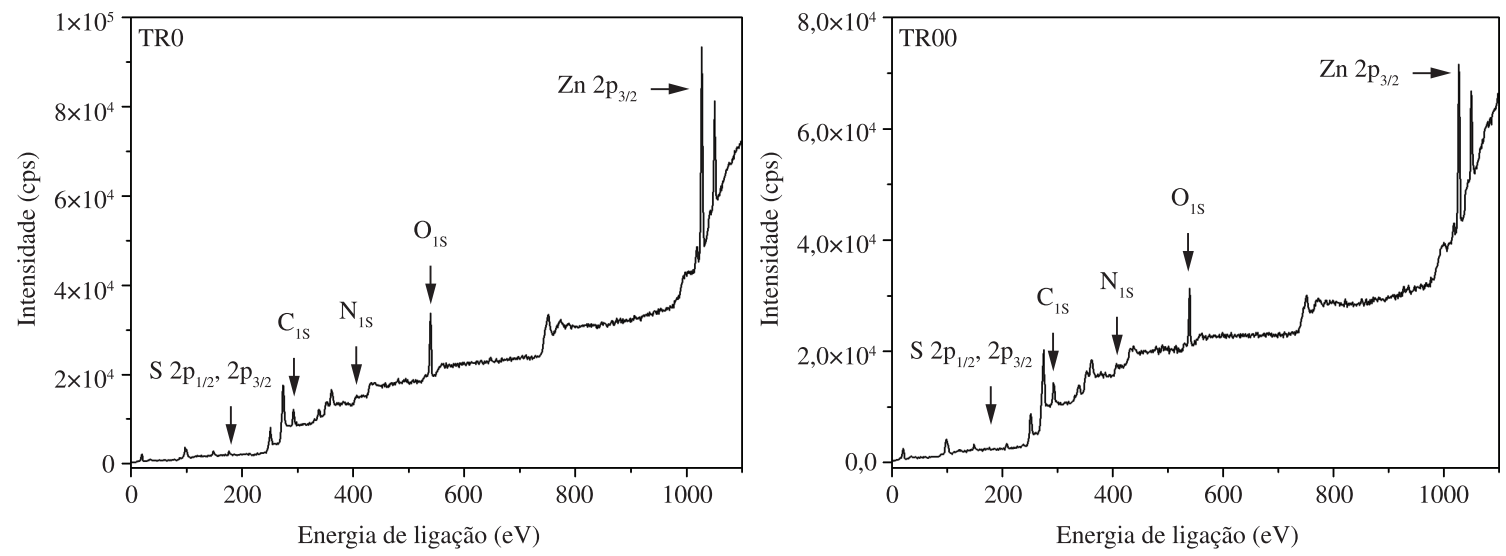

Figura 4. Espectros de XPS dos HSLs intercalados com os corantes aniônicos. 
quantitativa para o sistema HSL-TR0 ( $\mathrm{Zn}=20,229$ e $\mathrm{S}=4,033)$. Apesar da pequena contaminação de hidroxicloreto de zinco no HSL-TR0 e íons cloreto intercalados, devido ao seu baixo limite de detecção, esse elemento não foi detectado em nenhuma das amostras.

As curvas de análise térmica (TGA/DTA) dos compostos HSLTR0 e HSL-TR00 são mostradas na Figura 5.

No composto HSL-TR0, duas perdas de massa que totalizam $11,95 \%$ são observadas entre a temperatura ambiente e $215^{\circ} \mathrm{C}$, sendo esses eventos atribuídos à perda de água fisissorvida e intercalada e estão associados a dois picos endotérmicos na curva de DTA com máximos em 106 e $168^{\circ} \mathrm{C}$. Em seguida observa-se um processo de perda de massa largo de $41,26 \%$, atribuído à oxidação total do material orgânico originando $\mathrm{ZnO}$, como comprovado por medidas de difração de raios $\mathrm{X}$ do resíduo (não mostrado). Esse evento está associado a um pico exotérmico largo em $394{ }^{\circ} \mathrm{C}$, com um ombro em $595^{\circ} \mathrm{C}$ e o teor de resíduos final é de $46,8 \%$.

No caso do composto HSL-TR00, observa-se uma perda de massa de $10,8 \%$ entre a temperatura ambiente e $215{ }^{\circ} \mathrm{C}$, associado a um pico endotérmico em $175^{\circ} \mathrm{C}$. Essa perda de massa pode ser atribuída ao processo de remoção de água fisissorvida já que a medida de FTIR exclui a possibilidade de água estrutural (Figura 3). Em seguida observa-se um pico exotérmico fino com máximo em $424{ }^{\circ} \mathrm{C}$, associado a uma perda de massa adicional de $49.5 \%$, relativa à total oxidação da amostra à $\mathrm{ZnO}$ (teor de resíduos de 40,05\%).

Em função dos resultados das medidas de análise térmica, as seguintes fórmulas foram obtidas: $\mathrm{Zn}_{5}(\mathrm{OH})_{8}(\mathrm{TR} 0)_{0,86}(\mathrm{Cl})_{1,14} .5,77$ $\mathrm{H}_{2} \mathrm{O}$ e $\mathrm{Zn}_{5}(\mathrm{OH})_{8}(\mathrm{TR} 00)_{1,17}(\mathrm{Cl})_{0,83} \cdot 6,07 \mathrm{H}_{2} \mathrm{O}$, para a intercalação dos ânions de TR0 e TR00, respectivamente. Apesar da fórmula do pigmento HSL-TR0 ter sido obtida, é importante ressaltar que essa amostra está levemente contaminada com hidroxicloreto de zinco o que faz com que a fórmula seja ligeiramente desviada da fórmula proposta. Esses valores estão em boa concordância com os valores obtidos por espectroscopia UV-Vis, quando do ataque das amostras com $\mathrm{HCl}$ e das medidas de XPS, quando para a amostra HSL-TR0, a relação $\mathrm{Zn} / \mathrm{S}$ teórico é de 5,8 enquanto que o valor experimental é de 5,02 ( $\mathrm{Zn}=20,229$ e $\mathrm{S}=4,033 \%$ atômico). Os valores também estão próximos daqueles obtidos quando da intercalação de alaranjado de metila e alaranjado II na mesma matriz lamelar, onde somente cerca de um tetraedro de zinco é ocupado pelo ânion do corante, quando da restrição do teor de corante aniônico, em relação à estequiometria esperada ${ }^{[30]}$. Além do menor teor utilizado nas sínteses, a densidade de pilastras do ânion intercalado é restrita devido às grandes sessões transversais dos ânions intercalados, em relação ao espaço disponível entre as lamelas, o que limita a sua entrada por razões estéreas. Os demais sítios positivos das lamelas, não ocupados pelos ânions do corante, são ocupados pelos íons cloreto hidratados.

Os difratogramas de raios $\mathrm{X}$ dos filmes de PVA e compósitos de PVA contendo os hidroxissais intercalados com os corantes aniônicos (pigmentos laranja) são mostrados na Figura 6 .

No PVA puro, observa-se um pico de difração largo posicionado em aproximadamente $20^{\circ}$ (em $2 \theta$ ), além de um ombro na região de $22.5^{\circ}$ (em 20), os quais correspondem aos planos 10-1 e $101 \mathrm{da}$ estrutura cristalina do PVA atático ${ }^{[33]}$.

No caso do PVA:HSL-TR0, picos de difração largos e de baixa intensidade foram observados em $12,2 \AA$ para a concentração de $0,5 \%, 13,2$ e $23,8 \AA$, para a concentração de $2 \%$ e $11,1,15,3$ e $22,4 \AA$
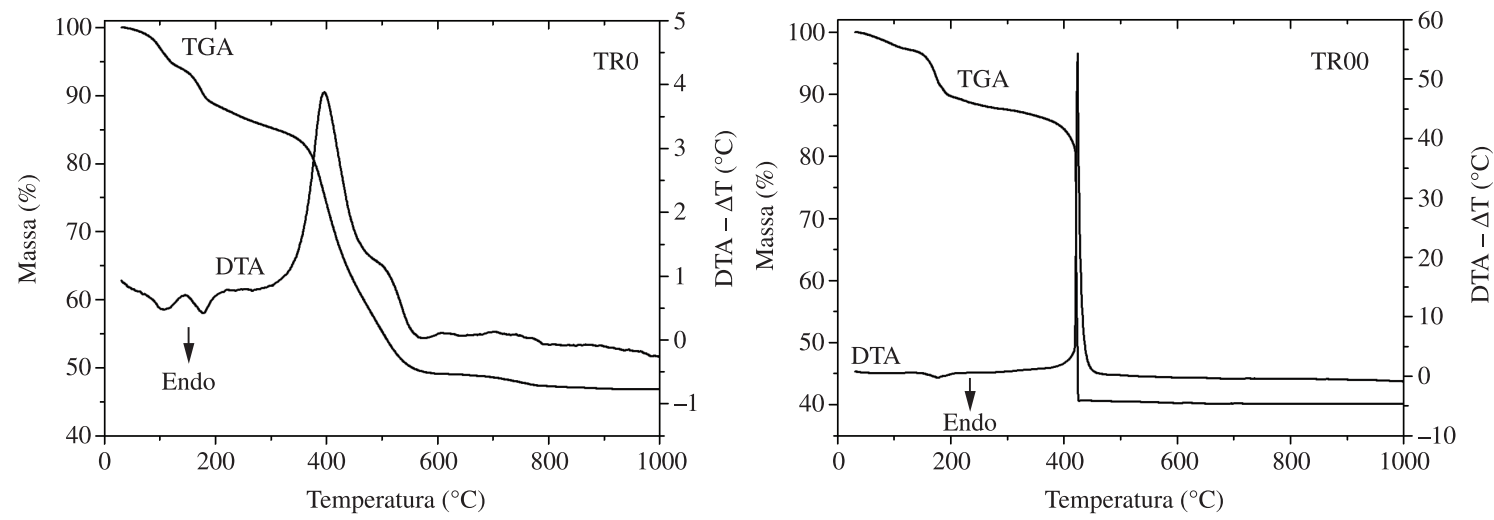

Figura 5. Curvas de TGA/DTA para os HSLs intercalados com os corantes aniônicos.
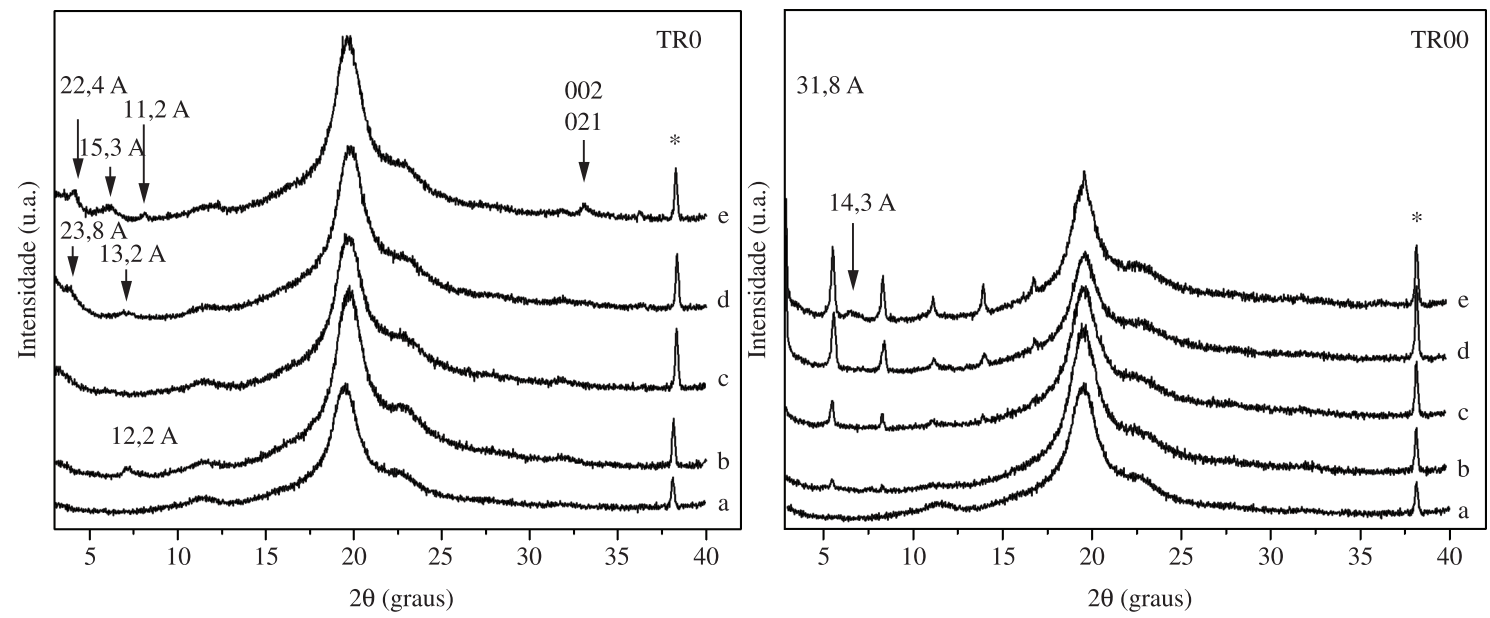

Figura 6. Difratogramas de raios X dos filmes de PVA e compósitos de PVA contendo os hidroxissais lamelares de zinco intercalados com os corantes aniônicos (PVA:HSL-TR0 e PVA:HSL-TR00). * = pico 111 do porta-amostras de Al. 
para a concentração de $4 \%$. Como nenhum dos picos de difração pôde ser atribuído a estrutura do pigmento, essa é uma evidência de que o composto intercalado com o corante aniônico está sendo delaminado/esfoliado no polímero, com formação de compostos intermediários, provavelmente com a intercalação de moléculas de PVA e/ou água. Em todos os casos observa-se o pico de difração com índice 111, relativo ao porta-amostras de alumínio, indicado com um asterisco.

A diferença fundamental entre o ânion derivado da tropaeolina 0 e tropaeolina 00 é a existência de duas hidroxilas na estrutura do ânion da tropaeolina 0 , o que certamente torna o composto mais hidrofílico, justificando a delaminação/esfoliação na matriz do PVA. Outro fato que atesta a presença de lamelas do HSL no compósito é a observação do pico largo na região de $33^{\circ}$, que são característicos das reflexões 002 e 021 , indexadas na estrutura do hidroxinitrato de zinco ${ }^{[25]}$. Essas reflexões não são observadas no compósito contendo o HSL-TR00, pelo fato de que na amostra não delaminada/esfoliada, os picos basais são de maior intensidade, mascarando a presença dos picos não basais.

No caso do compósito PVA:HSL-TR00, a partir do teor de $1 \%$ são observados picos de difração atribuídos ao HSL-TR00, com distância basal levemente aumentada para 31,8 A, os quais crescem continuamente de intensidade, o que mostra a manutenção da estrutura lamelar na matriz no PVA. Essa é uma evidência clara da obtenção de compósitos não delaminados/esfoliados, embora na concentração de $4 \%$, um pequeno pico de difração tenha sido observado em 14,3 Å, evidenciado uma parcial intercalação do PVA entre as lamelas do HSL. Mais uma vez, diferenças observadas por todas as técnicas utilizadas demonstram que os dois ânions são intercalados de formas distintas, o que atesta também os comportamentos distintos na formação dos compósitos.

A Figura 7 mostra as curvas de DSC (aquecimento = A, C; esfriamento $=\mathrm{B}$, D) dos filmes de PVA contendo os hidroxissais intercalados com os corantes aniônicos (A,B = PVA:HSL-TR0; C,D = PVA:HSL-TR00) e os dados são sumarizados na Tabela 1 e 2.

Observa-se claramente das curvas que os compósitos PVA:HSLTR0 e PVA:HSL-TR00 têm seus picos de fusão dentro na mesma faixa de temperatura de $218,6{ }^{\circ} \mathrm{C}$ do PVA puro ${ }^{[34]}$, independente do teor de carga e do tipo de pigmento utilizado (Tabela 1). As entalpias de fusão, de um modo geral, são gradativamente reduzidas com o aumento de carga (de 33,45 J/g no PVA puro para $28,75 \mathrm{~J} / \mathrm{g}$ e 24,7 J/g para os compósitos PVA:HSL-TR0 e PVA:HSL-TR00, respectivamente (Tabela 1). Durante o ciclo de resfriamento, picos são deslocados para menores temperaturas, tendendo ao estado amorfo principalmente para o compósito PVA:HSL-TR0, onde são esperadas maiores interações da carga com o polímero principalmente pelo seu maior caráter hidrofílico. No caso do compósito PVA:HSLTR00, picos de cristalização são deslocados para maiores e menores temperaturas porém mesmo com $4 \%$ de carga, a matriz polimérica se encontra com bom índice de cristalinidade, evidenciando uma menor interação entre as fases, como já atestado por difração de raios X (Figura 6).

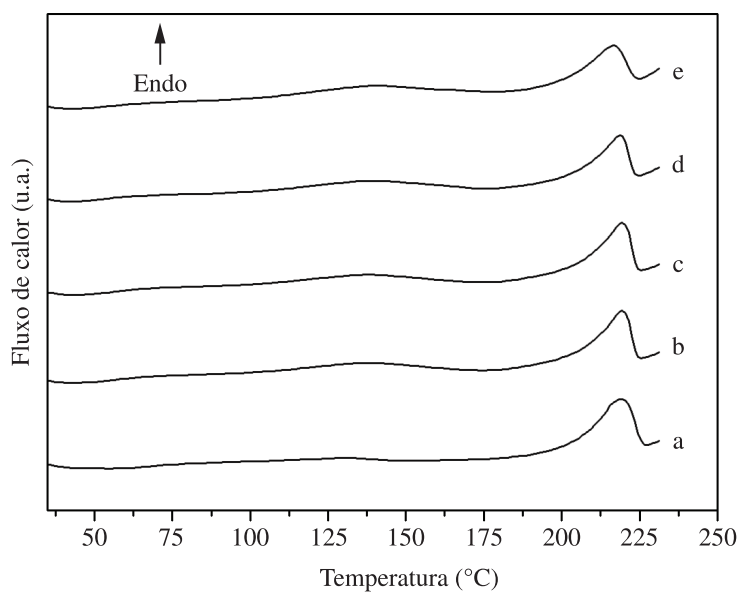

(A)

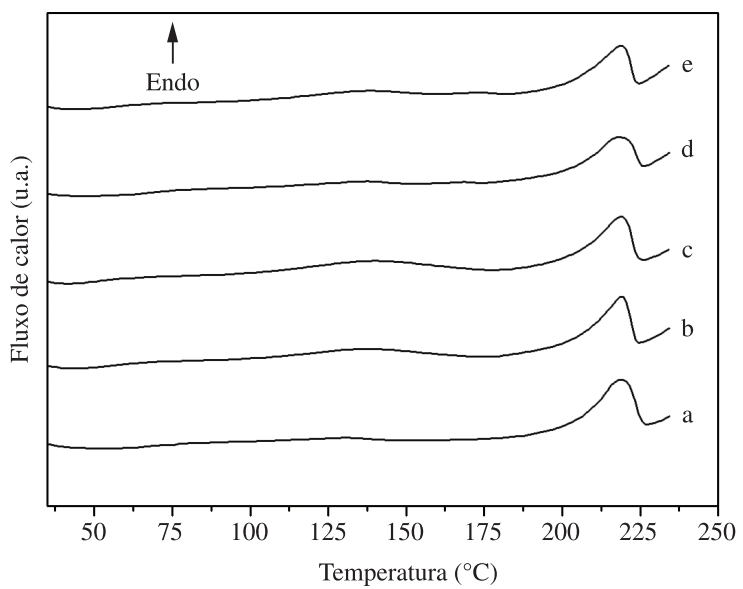

(C)

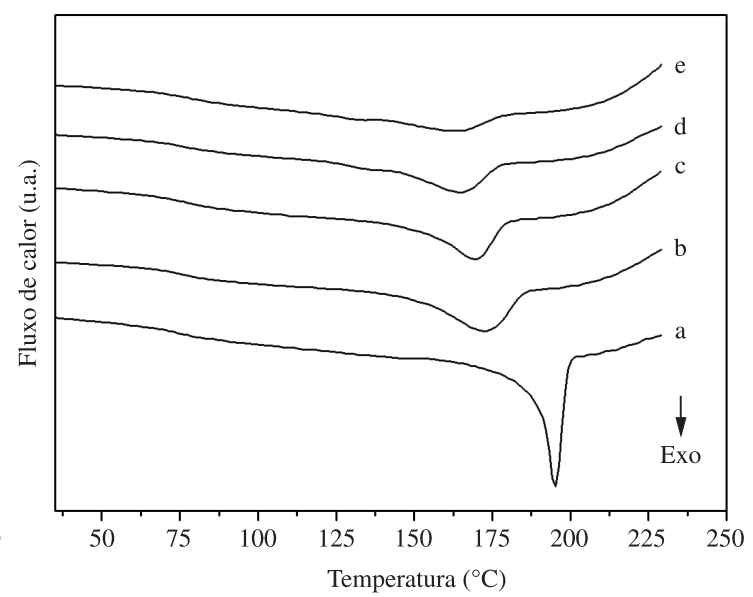

(B)

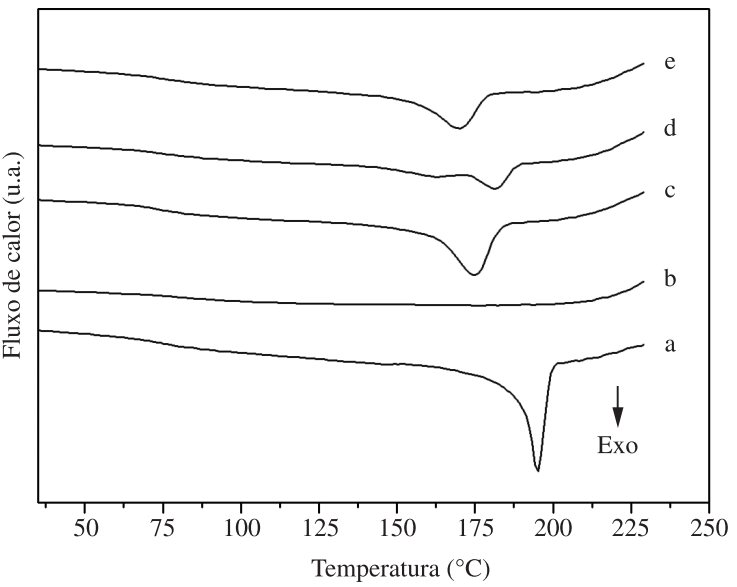

(D)

Figura 7. Curvas de DSC (aquecimento = A,C; esfriamento = B,D) dos compósitos PVA utilizando como carga os HSLs intercalados com os corantes aniônicos (A,B = HSL-TR0; $\mathrm{C}, \mathrm{D}=$ HSL-TR00). $\mathrm{a}=\mathrm{PVA}$ puro e compósitos contendo: $\mathrm{b}=0,5 \% ; \mathrm{c}=1 \% ; \mathrm{d}=2 \% ; \mathrm{e}=4 \%$ de carga em relação à massa do PVA. 
O efeito de diminuição do índice de cristalinidade mostra claramente a interação do PVA com o pigmento, diminuindo as possibilidades do estabelecimento de ligações de hidrogênio entre as cadeias poliméricas e consequentemente formação de regiões cristalinas, além de possíveis processos de oxidação hidrolítica ou termolítica das moléculas do PVA ${ }^{[35]}$.

A Figura 8 mostra as imagens dos filmes dos compósitos, obtidas com uma câmera digital. Observa-se que os filmes são coloridos, transparentes e relativamente homogêneos e que a intensidade da coloração é proporcional ao teor de pigmento. Mesmo com $4 \%$ de carga, os filmes são transparentes demonstrando que as dimensões das partículas são menores que o comprimento da luz visível e que se encontram relativamente bem dispersas na matriz polimérica, fato que é altamente desejável para aplicações dos materiais na forma de filmes, em indústrias variadas.
A Tabela 3 e a Figura 9 mostram os resultados das propriedades mecânicas dos filmes dos compósitos PVA:HSL-TR0 e PVA:HSLTR00.

De modo geral, as cargas inorgânicas deveriam deixar os filmes mais rígidos, aumentando o módulo, a tensão máxima e diminuindo o alongamento. Nos filmes avaliados, devido à capacidade plastificante da água, especialmente no caso do PVA, o qual possui macromoléculas polihidroxiladas, o que permite o estabelecimento de ligações de hidrogênio entre a cadeia polimérica e as moléculas de água, a maioria dos filmes apresenta um baixo efeito de reforço das cargas inorgânicas. Embora o HSL-TR0 tenha sido delaminado/ esfoliado no polímero (Figura 6), esse efeito da carga se perde devido ao efeito plastificante da água. Esse efeito se torna mais evidente somente após eliminação da maioria do teor de água, quando as propriedades mecânicas são aumentadas por um fator próximo de $10^{[30,36,37]}$. Para ambas as cargas o módulo primeiramente

Tabela 1. Dados de fusão dos filmes obtidos por DSC.

\begin{tabular}{lcccc}
\hline Composto & Inicio do evento $\left({ }^{\circ} \mathbf{C}\right)$ & Término do evento $\left({ }^{\circ} \mathbf{C}\right)$ & Pico de fusão $\left({ }^{\circ} \mathbf{C}\right)$ & Entalpia de fusão $(\mathbf{J} / \mathbf{g})$ \\
\hline PVA Puro & 201,9 & 226,2 & 218,6 & 33,45 \\
PVA:HSL-TR00 0,5\% & 205,4 & 224,4 & 218,4 & 32,36 \\
PVA:HSL-TR00 1,0\% & 204,2 & 224,8 & 218,3 & 36,23 \\
PVA:HSL-TR00 2,0\% & 203,3 & 225,9 & 217,9 & 24,40 \\
PVA:HSL-TR00 4,0\% & 206,4 & 224,2 & 218,2 & 24,70 \\
PVA:HSL-TR0 0,5\% & 205,4 & 225,0 & 218,8 & 35,34 \\
PVA:HSL-TR0 1,0\% & 202,9 & 223,8 & 217,9 & 34,37 \\
PVA:HSL-TR0 2,0\% & 204,0 & 223,6 & 218,0 & 28,18 \\
PVA:HSL-TR0 4,0\% & 200,5 & 223,2 & 216,4 & 28,75 \\
\hline
\end{tabular}

Tabela 2. Dados de cristalização dos filmes obtidos por DSC.

\begin{tabular}{ccccc}
\hline Composto & Inicio do evento $\left({ }^{\circ} \mathbf{C}\right)$ & Término do evento $\left({ }^{\circ} \mathbf{C}\right)$ & Pico do evento $\left({ }^{\circ} \mathbf{C}\right)$ & $\begin{array}{c}\text { Entalpia de cristalização } \\
(\mathbf{J} / \mathbf{g})\end{array}$ \\
\hline PVA Puro & 187,1 & 200,2 & 194,8 & $-52,32$ \\
PVA:HSL-TR00 0,5\% & nd & nd & nd & nd \\
PVA:HSL-TR00 1,0\% & 161,7 & 182,9 & 174,5 & $-33,35$ \\
PVA:HSL-TR00 2,0\% & 174,0 & 188,2 & 181,6 & $-6,36$ \\
PVA:HSL-TR00 4,0\% & 159,6 & 178,3 & 169,9 & $-15,05$ \\
PVA:HSL-TR0 0,5\% & 151,8 & 184,9 & 172,3 & $-31,92$ \\
PVA:HSL-TR0 1,0\% & 152,4 & 179,2 & 169,1 & $-27,42$ \\
PVA:HSL-TR0 2,0\% & 145,4 & 177,1 & 164,7 & $-16,61$ \\
PVA:HSL-TR0 4,0\% & 144,6 & 178,2 & 164,0 & $-13,09$ \\
\hline
\end{tabular}

nd = não detectado.

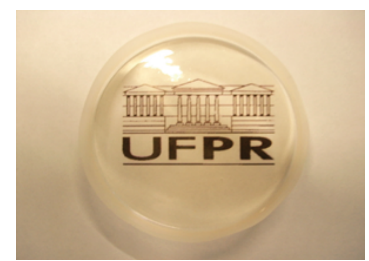

(a)

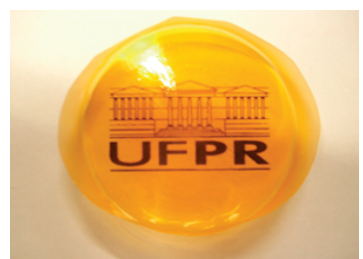

(b)

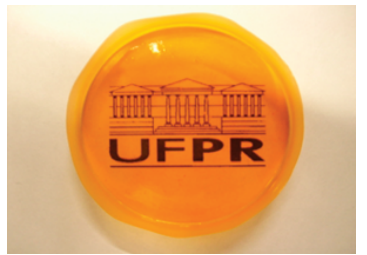

(c)

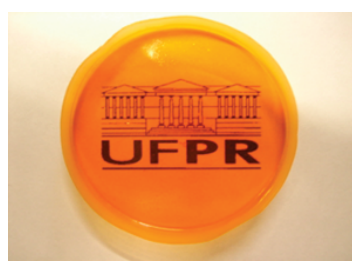

(d)

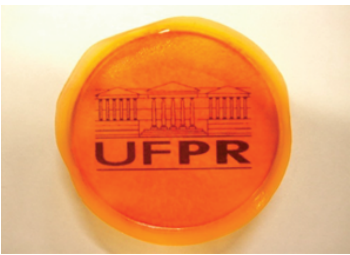

(e)

Figura 8. Imagens dos filmes de PVA e após adição do pigmento HSL-TR0, obtidos com uma câmera digital. a) PVA puro; b) $0,5 \%$; c) $1,0 \%$; d) $2 \%$; e) $4 \%$ de carga, em relação à massa do PVA. 
Tabela 3. Propriedades mecânicas dos filmes dos compósitos de PVA reforçados com os pigmentos laranja.

\begin{tabular}{lccc}
\hline Amostras - umidade de 65\% & Módulo de Young (MPa) & Tensão máxima (MPa) & Alongamento máximo (\%) \\
\hline PVA & $140,72 \pm 27,01$ & $36,26 \pm 2,78$ & $523,63 \pm 18,67$ \\
PVA:HSL-TR0 0,5\% & $130,69 \pm 3,96$ & $29,88 \pm 6,51$ & $519,43 \pm 31,38$ \\
PVA:HSL-TR0 1\% & $148,28 \pm 1,50$ & $34,17 \pm 7,43$ & $601,26 \pm 24,23$ \\
PVA:HSL-TR0 2\% & $168,03 \pm 5,31$ & $34,49 \pm 2,18$ & $490,24 \pm 45,12$ \\
PVA:HSL-TR0 4\% & $163,54 \pm 5,18$ & $23,97 \pm 2,15$ & $281,65 \pm 10,13$ \\
PVA:HSL-TR00 0,5\% & $127,59 \pm 7,68$ & $39,20 \pm 1,48$ & $416,92 \pm 16,57$ \\
PVA:HSL-TR00 1\% & $125,17 \pm 0,90$ & $34,32 \pm 0,69$ & $410,71 \pm 8,10$ \\
PVA:HSL-TR00 2\% & $188,30 \pm 26,18$ & $38,90 \pm 2,30$ & $296,12 \pm 36,35$ \\
PVA:HSL-TR00 4\% & $201,55 \pm 13,39$ & $36,59 \pm 2,07$ & $323,03 \pm 48,47$
\end{tabular}

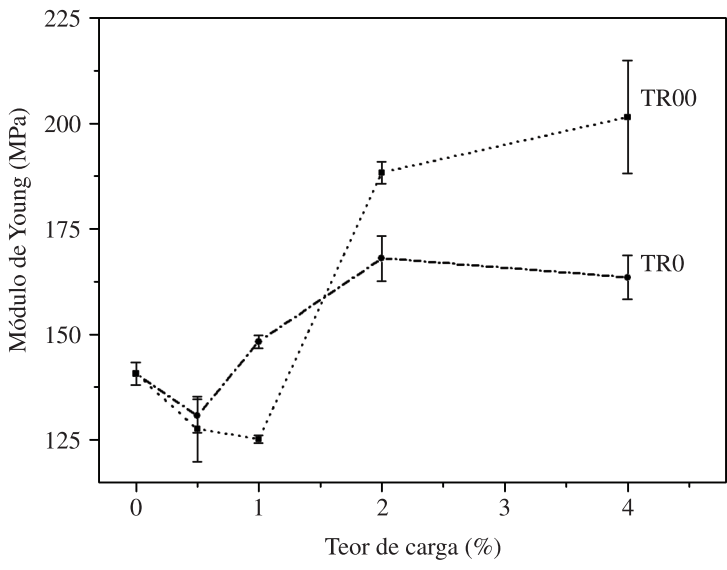

(a)

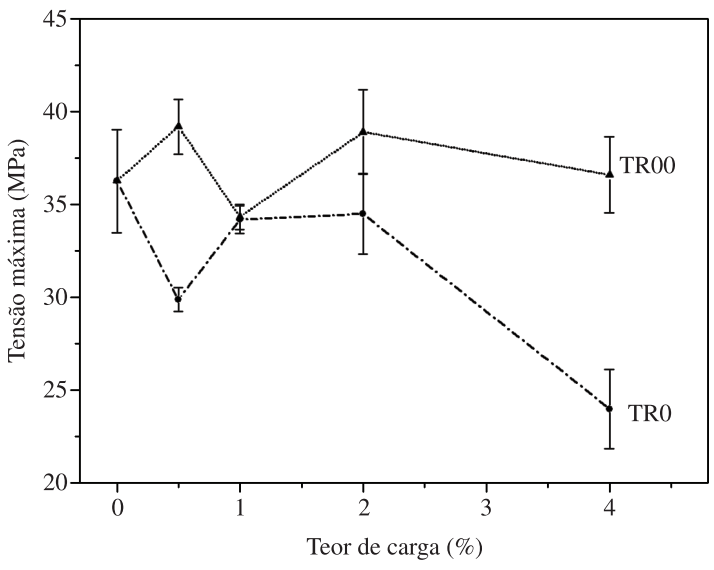

(b)

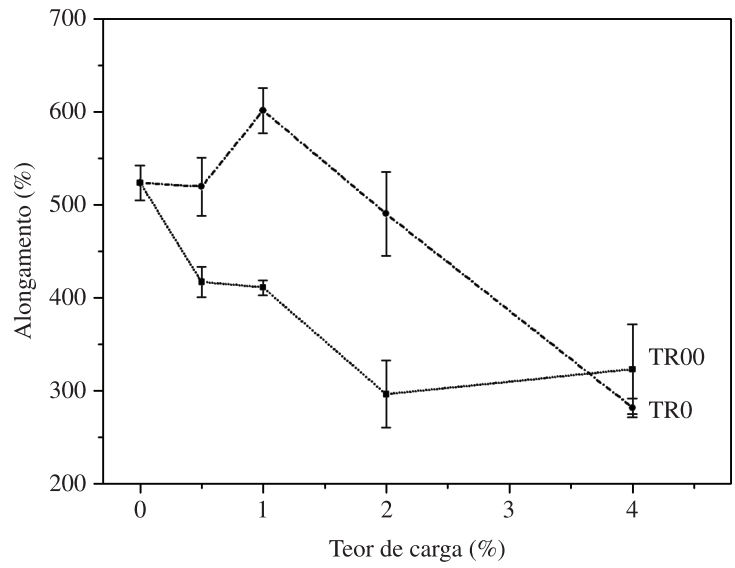

(c)

Figura 9. Medidas de Módulo de Young (a), tensão máxima (b) e alongamento (c), dos filmes de PVA e seus compósitos PVA:HSL-TR0 e PVA:HSL-TR00.

decresce e aumenta após $1 \%$, sendo o efeito mais pronunciado no caso de $4 \%$ de HSL-TR00 no PVA.

Para a tensão máxima, quando o compósito PVA:HSL-TR00 é avaliado, o valor cai quando do uso de $0,5 \%$ de carga e depois aumenta com o aumento do teor. Para o caso da PVA:HSL-TR0 ocorre um efeito contrário, com $0,5 \%$ de carga se observa um aumento da tensão máxima e depois ocorre uma queda progressiva. O alongamento cresce para o compósito PVA:HSL-TR0 até $1 \%$ de carga e cai após esse valor enquanto que para o caso da PVA:HSLTR00, a queda é continua até o teor de $2 \%$ de carga.

\section{Conclusões}

Os ânions derivados dos corantes azo laranja tropaeolina 0 e tropaeolina 00 foram intercalados com sucesso no hidroxissal lamelar de zinco. Devido à restrição do teor de corante aniônico em relação à estequiometria esperada, houve a intercalação dos ânions derivados do corante e co-intercalação de íons cloreto hidratados. Devido às dimensões dos ânions dos corantes, esses definem a distância basal dos compostos. No caso da intercalação do ânion derivado da tropaeolina 0 , houve uma pequena segregação de uma fase contaminante de hidroxicloreto de zinco, onde somente o íon cloreto hidratado é intercalado.

Após intercalação, os pigmentos laranja foram utilizados como cargas no PVA, obtendo-se filmes transparentes e coloridos, o que atesta a boa dispersão dos compostos lamelares no polímero e potencial aplicação. Os dois pigmentos apresentaram diferentes comportamentos após dispersão no polímero, no caso da tropaeolina 0 , devido as características mais hidrofílicas do corante, os cristais foram quase que totalmente delaminados (esfoliados), enquanto que 
no caso da tropaeolina 00 , a estrutura permaneceu intacta, como atestado pelas medidas de difração de raios $\mathrm{X}$.

As medidas de DSC atestam que no processo de fusão as temperaturas se mantêm praticamente constantes e que durante o processo de cristalização, os materiais diminuem a sua cristalinidade até a amorfização quase completa, especialmente para o caso do hidroxissal intercalado com o corante derivado da tropaeolina 0 , o qual possui caráter mais hidrofílico.

As propriedades mecânicas dos compósitos foram avaliadas e diferentes comportamentos foram observados para a intercalação dos dois corantes, o que atesta diferentes interações com os cristais do hidroxissal lamelar. Estudos estão em andamento para melhor compreensão dos fenômenos envolvidos na intercalação, além da dispersão dos pigmentos em polímeros hidrofílicos e hidrofóbicos.

\section{Agradecimentos}

Os autores gostariam de agradecer as agências de fomento CAPES - Coordenação de aperfeiçoamento de pessoal de nível superior, FINEP - Financiadora de estudos e projetos e $\mathrm{CNPq}$ - Conselho nacional de desenvolvimento científico e tecnológico, por financiar o presente projeto e ao Laboratório de Análise de Minerais e Rochas (LAMIR - UFPR), pelas análises de TGA/DTA e Profa. Marilda Munaro (Lactec), pelas medidas de DSC.

\section{Referências Bibliográficas}

1. Usuki, A.; Kawasumi, M.; Kojima, Y.; Okada, A.; Kurauchi, T. \& Kamigaito, O. - J. Mat. Res., 8, p.1174 (1993). http://dx.doi. org/10.1557/JMR.1993.1174

2. Usuki, A.; Kojima, Y.; Kawasumi, M.; Okada, A.; Fukushima, Y.; Kurauchi, T. \& Kamigaito, O. - J. Mat. Res., 8, p.1179 (1993). http:// dx.doi.org/10.1557/JMR.1993.1179

3. Kojima, Y.; Usuki, A.; Kawasumi, M.; Okada, A.; Fukushima, Y.; Kurauchi, T. \& Kamigaito, O. - J. Mat. Res., 8, p.1185 (1993). http:// dx.doi.org/10.1557/JMR.1993.1185

4. Leroux, F. \& Besse, J. P. - Chem. Mater., 13, p.3507 (2001). http:// dx.doi.org/10.1021/cm0110268

5. Zammarano, M.; Bellayer, S.; Gilman, J. W.; Franceschi, M.; Beyer, F. L.; Harris, R. H. \& Meriani, S. - Polymer., 47, p.652 (2006). http:// dx.doi.org/10.1016/j.polymer.2005.11.080

6. Li, L.; Ma, R. Z.; Ebina, Y.; Iyi, N. \& Sasaki, T. - Chem. Mater., 17, p.4386 (2005). http://dx.doi.org/10.1021/cm0510460

7. Moujahid, E. M.; Besse, J. P. \& Leroux, F. - J. Mater. Chem., 12, p.3324 (2002). http://dx.doi.org/10.1039/b205837p

8. Liao, C. S. \& Ye, W. B. - Electrochim. Acta, 49, p.4993 (2004). http:// dx.doi.org/10.1016/j.electacta.2004.06.018

9. Forano, C. - "Environmental remediation involving layered double hydroxides", in: Clay Surfaces: Fundamentals and applications, cap.15, Wypych F. \& Satyanarayana, K. G. (ed.), Elsevier, Amsterdam (2004). http://dx.doi.org/10.1016/S1573-4285(04)80050-4

10. Wypych, F. \& Satyanarayana, K. G. - J. Colloid Interface Sci., 285, p.532 (2005).

11. Wypych, F.; Arizaga, G. G. C. \& Satyanarayana, K. G. - "Synthetic layered materials/polymer nanocomposites", in: Polymer Nanocomposite Research Advances, cap.4, Thomas, S. \& Zaikov, G.E. (ed.), Nova Science Publishers, Inc., New York (2008).

12. Li, B. G.; Hu, Y.; Zhang, R.; Chen, Z. Y. \& Fan, W. C. - Mat. Res. Bull., 38, p.1567 (2003). http://dx.doi.org/10.1016/S00255408(03)00203-4

13. Arizaga, G. G. C.; Satyanarayana, K. G. \& Wypych, F. - Solid State Ionics, 178, p.1143 (2007). http://dx.doi.org/10.1016/j.ssi.2007.04.016
14. Meyn, M.; Beneke, K. \& Lagaly, G. - Inorg. Chem., 32, p.1209 (1993). http://dx.doi.org/10.1021/ic00059a030

15. Yacaman, M. J.; Rendon, L.; Arenas, J. \& Puche, M. C. J. - Science, 273, p.223 (1996). http://dx.doi.org/10.1126/science.273.5272.223

16. Goes, A. M.; Carvalho, S.; Oréfice, R. L.; Averous, L.; Custódio, T. A.; Pimenta, J. G.; Souza, M. B.; Branciforti, M. C. \& Bretas, R. E. S. - Polímeros, 22, p.34 (2012). http://dx.doi.org/10.1590/S010414282012005000012

17. Passos, A. A.; Tavares, M. I. B.; Cucinelli Neto, R.; Moreira, L. A. \& Ferreira, A. G. - Polímeros, 21, p.98 (2011). http://dx.doi.org/10.1590/ S0104-14282011005000023

18. Resende, D. K.; Dornelas, C. B.; Tavares, M. I. B.; Gomes, A. S.; Moreira, L. A.; Cabral, L. M. \& Simeoni, L. A. - Polímeros, 20, p.131 (2010). http://dx.doi.org/10.1590/S0104-14282010005000031

19. Medeiros, V. N.; Araujo, E. M.; Maia, L. F.; Pereira, O. D.; Arimateia, R. R. \& Paz, R. A. - Polímeros, 18, p.302 (2008). http://dx.doi. org/10.1590/S0104-14282008000400008

20. Dornelas, C. B.; Resende, D. K.; Tavares, M. I. B.; Gomes, A. S. \& Cabral, L. M. - Polímeros, 18, p.187 (2008). http://dx.doi.org/10.1590/ S0104-14282008000200017

21. Marangoni, R.; Mikowski, A. \& Wypych, F. - J. Colloid Interface Sci., 351, p.384 (2010).

22. Marangoni, R.; Gardolinski, J. E. F. C.; Mikowski, A. \& Wypych, F. - J. Solid State Electrochem., 15, p.303 (2011). http://dx.doi.org/10.1007/ s10008-010-1056-2

23. Moulder, J. F.; Sobol, W. F. \& Bomben, K. D. - "Handbook of X-ray Photoelectron Spectroscopy”, Eden Prairie (1995).

24. XPS International. - "754 Leona Lane Mountain View”, Ca, 94040, USA. (Spectral Data Processor Software Version 3.2).

25. Stählin, W. \& Oswald, H. R. - Acta Crystalograp. B, 26, p.860 (1970). http://dx.doi.org/10.1107/S0567740870003230

26. Allmann. R. - Zeit. Kristallog., 126, p.417 (1968).

27. Melanova, K.; Benes, L.; Zima, V. \& Svoboda, J. - J. Inclus. Phen. Macroc. Chem., 51, p. 97 (2005).

28. Illaik, A.; Vuillermoz, C.; Commereuc, S.; Taviot-Gheho, C.; Verney, V. \& Leroux, F. - J. Phys. Chem. Solids, 69, p.1361 (2008). http:// dx.doi.org/10.1016/j.jpcs.2007.10.019

29. Géraud, E.; Bouhent, M. M.; Derriche, Z.; Leroux, F.; Prevot, V. \& Forano C. - J. Phys. Chem. Solids, 68, p.818-823 (2007). http://dx.doi. org/10.1016/j.jpcs.2007.02.053

30. Silva, M. A.; Marangoni, R.; Cursino, A. C. T.; Schreiner, W. H. \& Wypych, F. - Mat. Chem. Phys. 134, p.392 (2012).

31. Wang, J.; Ren, X. M.; Feng, X. S.; Liu, S. Y. \& Sun, D. J. - J. Colloid Interface Sci., 318, p.337 (2008).

32. Zhang, P.; Qian, Q.; Shi, H.; Yang, J. \& Frost, R. L. - J. Colloid Interface Sci., 365, p.110 (2012).

33. Ricciardi, R.; Auriemma, F.; Rosa, C. \& Lauprêtre, F. - Macromol., 37, p.1921 (2004). http://dx.doi.org/10.1021/ma035663q

34. Holland, B. J. \& Hay, J. N. - Polymer, 42, p.6775 (2001). http://dx.doi. org/10.1016/S0032-3861(01)00166-5

35. Uddin, A.J.; Fujie, M.; Sembo, S. \& Gotoh, Y. - Carboh. Pol., 87, p.799 (2012). http://dx.doi.org/10.1016/j.carbpol.2011.08.071

36. Ramaraj, B.; Nayak, S.K. \& Yoon, K. R. - J. Appl. Pol. Sci., 116, p.1671 (2010).

37. Huang, S.; Cen, X.; Zhu, H.; Yang, Z.; Yang, Y.; Tjiu, W. W. \& Liu, T. - Mat. Chem. Phys., 130, p.890 (2011). http://dx.doi.org/10.1016/j. matchemphys.2011.08.005

Enviado: $28 / 10 / 11$

Reenviado: $21 / 05 / 12$

Aceito: 04/06/12 